\title{
Where am I now and where do I want to be? Developing awareness of graduate attributes in pre-honours students
}

\author{
Maxine V. Swingler*1, Sarah Armour ${ }^{2}$, Jason Bohan', Heather Cleland-Woods', Gordon B. \\ Curry $^{3}$ \& Archie W.N. Roy ${ }^{2}$.
}

School of Psychology ${ }^{1}$, Careers Service ${ }^{2}$, School of Geographical and Earth Sciences ${ }^{3}$, University of Glasgow, Glasgow, Scotland.

${ }^{*}$ Corresponding author: Maxine.swingler@glasgow.ac.uk

Keywords: graduate attributes, employability, self-efficacy, pre-honours, professional networking

\begin{abstract}
There is increasing emphasis on the importance of making Graduate Attributes (GAs) explicit to students as part of their degree programme and the role of students themselves in proactively developing GAs. The aim of the present project was to encourage students to actively develop and reflect upon curricular and extra-curricular attributes at an earlier stage in their degree programme. To this end we developed and evaluated shortself-reflection exercises in second year (prehonours) psychology practical classes which asked students to reflect on their curricular and extra-curricular activities and on how the practical skills gained from these activities are linked to graduate attributes. Activities were followed by careers workshops focused on gaining confidence in communicating graduate attributes in an interview context, and the benefits of engaging with professional networking sites. We evaluated the impact of these activities on: 1) students' levels of selfefficacy in specific GAs before and after the inclass exercises; 2) students' confidence in presenting their GAs in an interview situation; 3) student awareness of professional networking sites. The activities resulted in increased self- efficacy ratings after the GAS reflection, increased confidence in presenting
\end{abstract}

their GAs after the careers workshops, and an increased awareness of professional networking sites. The effectiveness of these activities as a method to increase student engagement in developing their GAs will be discussed in the wider context of embedding GAs and employability in pre-honours programmes across STEM disciplines.

\section{Introduction}

Graduate attributes ${ }^{1}$ at the University of Glasgow are defined as "...the academic abilities, personal qualities and transferable skills which all students will have the opportunity to develop as part of their University of Glasgow experience." Specific attributes might include being academically excellent, critical thinkers, effective communicators and having an overall commitment to scholarship (see for a review Nicol, 2010). Developing these attributes are seen as important because they produce on one hand highly employable graduates but also global citizens who are effective members of society (Barrie, 2004). The integration of graduate attributes into the curriculum often takes the form of Personal Development Planning (PDP), capstone modules and standalone careers sessions delivered in the honours years of study (Wadkins \& Miller

\footnotetext{
${ }^{1}$ http://www.gla.ac.uk/students/attributes/
} 
Where am I now and where do I want to be? Developing awareness of graduate attributes in pre-honours students

2011). For example, Curry, Thomson \& Hill (2012) successfully developed student ePortfolios which are explicitly linked to GAs, and the social network Linkedln. However, it has been argued that neither of these methods really "embeds" employability (Akhurst 2005) and that awareness of GAs in the pre-honours years is typically low (Morris, Cranney, Jeong \& Mellish, 2013). It can be challenging to engage students in non-core activities, such as building PDP portfolios in large pre-honours classes, particularly as there is an increase in undergraduates who work part time or have voluntary work commitments while studying (Gbadamosi, Evans, Richardson \& Ridolfo, 2015; UCAS, 2011). In many STEM subjects, students often fail to appreciate what GA are and how courses develop these skills and in turn how these map on to the jobs market (HEA 2013; O'Leary, 2016), suggesting that further support from universities is needed for students to effectively market and evidence their individual GAs (Green, Hammer \& Star, 2009; Hugh-Jones \& Sutherland, 2007). Wakeham (2016) calls for courses to more explicitly map links between assessments, GA and careers guidance, recommending that "careers advice should play a stronger role in STEM degrees", and "graduates out to be encouraged to ... take greater responsibility for understanding, developing and engaging with their potential future career path" (p.3). The key challenge facing educators is how best to embed attribute development within the curriculum, such as using self and peerassessment (Cowan and Cherry, 2012). To address these issues, we used an integrated approach, utilising core teaching time for students to actively reflect upon GAs gained from the curriculum and wider student experience. Integrated activities were supported by optional careers workshops and a student led networking event.

\section{Activities}

\section{Integrated Activities: Psychology}

Pre-honours undergraduate psychology students participated in a class as part of the practical aspect of the level 2 Psychology course. The class was broadly named Applying Psychology and supported the applied psychology lecture course. Students watched the University of Glasgow video on GAs (http://www.gla.ac.uk/students/attributes/), followed by a class discussion on whether students were aware of the GAs and how they had experienced them. In a small group discussion, students recorded on a worksheet where they felt they had the opportunity to develop each of the GAs. The worksheet asked the students: "Where have you had the opportunity to develop the Graduate Attributes (GAs)? Please think about the Psychology course, your other courses as well as your experiences outside of University."

\section{Integrated Activities: Earth Sciences}

In the Earth Science degree, graduate attributes are introduced in level 1 in connection with career paths within the geological sciences, and in the level 2 practical course this theme is further developed with discussions on how to evidence GAs, practical experience of creating their own e-Portfolios, and using external platforms such as Linkedln for professional networking and careers research.

\section{Optional Activities: Psychology}

The integrated psychology class activities were followed by optional careers workshops focused on helping psychology students gain confidence in communicating GAs in an interview context, and the benefits of engaging with professional networking sites. Students were introduced to the main types of interview questions used by graduate recruiters (such as competency based and motivational) using the situation-task-action-result (STAR) approach to answering competency and attributes questions. This led to a practical exercise in pairs in which they used a person specification for an assistant psychologist role. Their task was to plan and give a response to a competency question framed around one of the essential or desirable criteria in the person specification. Their peer then gave feedback on how well their partner had answered the question, what was good and what could have been improved. The pair roles were then switched.

The Careers Service ran a student led networking event for Psychology students. Five graduate alumni working in a variety of psychology related professions participated, each sitting at a different table with students. The graduates rotated to another table after 
Where am I now and where do I want to be? Developing awareness of graduate attributes in pre-honours students

five minutes. The session lasted a total of 30 minutes with transition times between tables. This allowed for all attendees to take part, exposed students to a number of different career options and increased student confidence in asking questions, as they were seated in small groups with their peers.

\section{Outcomes}

\section{Integrated Activities: Psychology}

Psychology students were surveyed online before (time 1) and after (time 2) the class activities using a measure of student selfefficacy beliefs in the University of Glasgow GA Framework. The University of Glasgow Graduate Attribute (GA) matrix contains 10 GAs which have been developed through consultation with the staff and students of the University alongside employers. Self-efficacy is defined as "judgments of capabilities to organize and execute courses of action" (Bandura, 1986, p.391), is known to predict educational and career outcomes (Gore, 2006), and play a key role in transitions through university (Cheng, Pringle-Barnes, Edwards, 2015). Participants were asked: 'How confident do you feel personally when you think about the following GAs?' Each GA was listed next to a 5 point Likert scale with 1 as Very confident and 5 as Not very confident at all. A web link to the GAs was provided. Participants were also asked to record their gender (Male/ Female/ I'd rather not say), initials and day of birth, which acted as the unique identifier for each participant. This information was kept confidential, in accordance with the BPS code of human research ethics.

A total of 206 level 2 Psychology students completed the in-class survey as preparation for the GAs tasks at time 1 (146 female, 60 male), and 218 students completed the survey at time 2 (159 female, 59 male). Fluctuations in the number of participants are attributed to absence from class or issues with matching data between time 1 and time 2 .

\section{Results}

Figures 1 and 2 show the frequency (\%) of confidence rating for each time point, pre- and post- intervention. The most noticeable changes are in confidence as Subject
Specialists and Reflective Learners with an increase of around $10 \%$ respectively. Analysis was carried out using a Wilcoxon Signed-Rank test to determine differences in confidence levels on each GA between time 1 and time 2 . This suggests a significant confidence increase in 9 out of 10 GAs between time 1 (pre-class) and time 2 (post class); Subject Specialist $V=2725, p=0.001$, Investigative $\mathrm{V}=19.4, \mathrm{p}=0.001$, Independent and Critical Thinker $V=1694, p=0.01$, Resourceful and Responsible $V=2299, \quad p=0.001, \quad$ Effective Communicator $\mathrm{V}=2327, \mathrm{p}=0.001$, Adaptable $\mathrm{V}=1691, \mathrm{p}=0.001$, Experienced Collaborator. $\mathrm{V}=2123, \mathrm{p}=0.05$, Ethically and Socially Aware $V=2034, \quad p=0.05$ and Reflective Learner $V=1656, p=0.01$. No significant difference was found on Overall confidence as a member of the student community $V=1469, p=0.4$.

\section{Integrated Activities: Earth Sciences}

Student comments on completion of the Earth science practical classes indicate that they are more aware of the importance of evidencing generic skills in job application, and of the full range of potential career destinations that are open to them (after consulting alumni career profiles on Linkedln).

\section{Optional Activities: Psychology}

Twelve Level 2 Psychology students attended the workshops, and were asked to rate their current level of confidence or knowledge in presenting graduate attributes and skills, common types of interview questions, and use of person specification using a scale of 1 (Very confident) to 5 (not confident at all), before and after the workshops. We found in increase in confidence in presenting attributes and skills $(40 \%$ to $90 \%$ "quite confident"), and an increase in knowledge of common types of interview questions $(20 \%$ to $80 \%$ "quite confident"), and use of person specification ( $40 \%$ to $70 \%$ "quite confident").

A total of 66 psychology undergraduates attended the networking event, resulting in a capacity turnout. Of those attending, 38\% were level 1 and level 2 psychology students, indicating a relatively high level of engagement of pre-honours students compared to other networking events held by the careers service. 
Where am I now and where do I want to be? Developing awareness of graduate attributes in pre-honours students

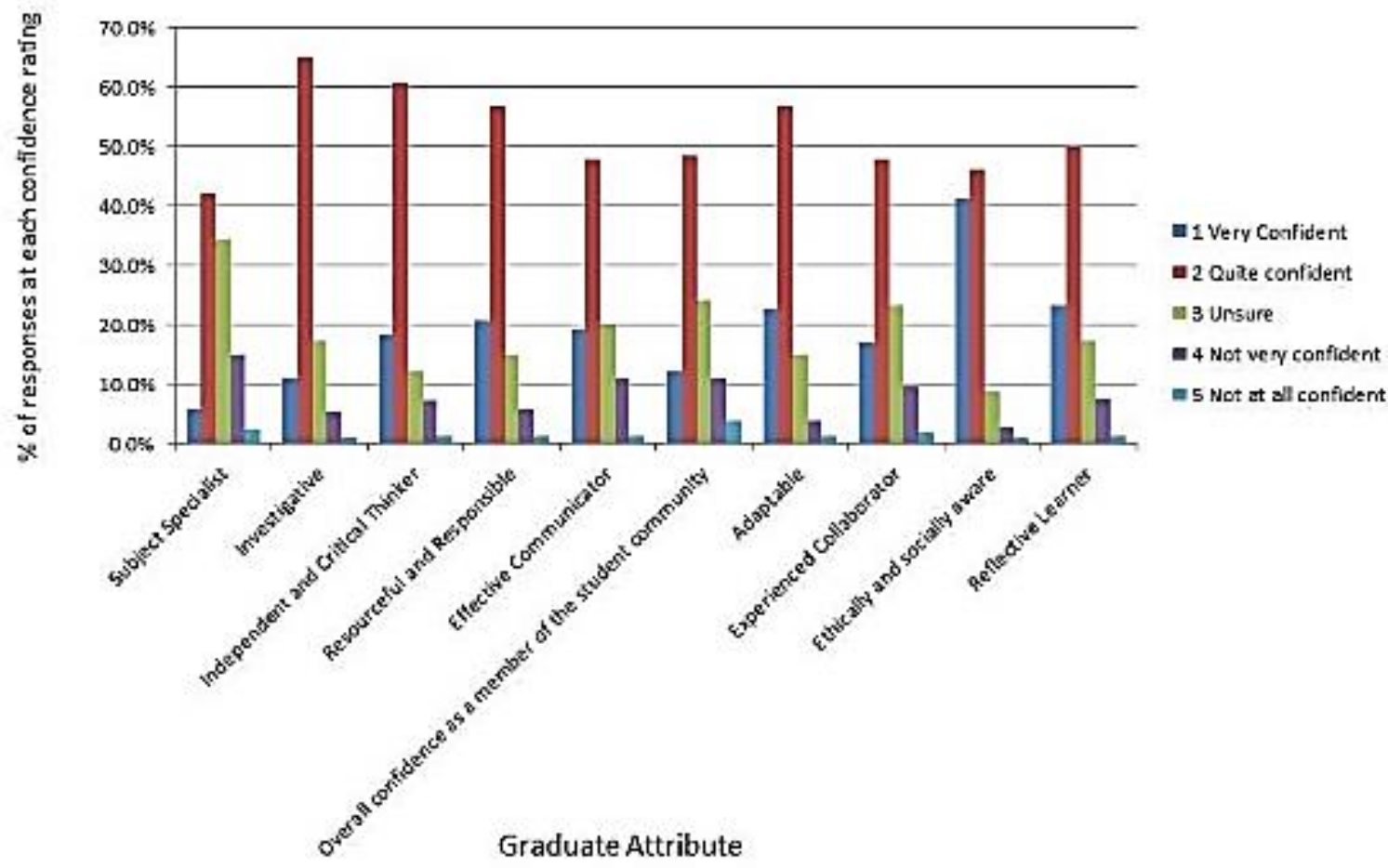

Figure 1 Frequency of rating by GA at Time 1 (pre-intervention)

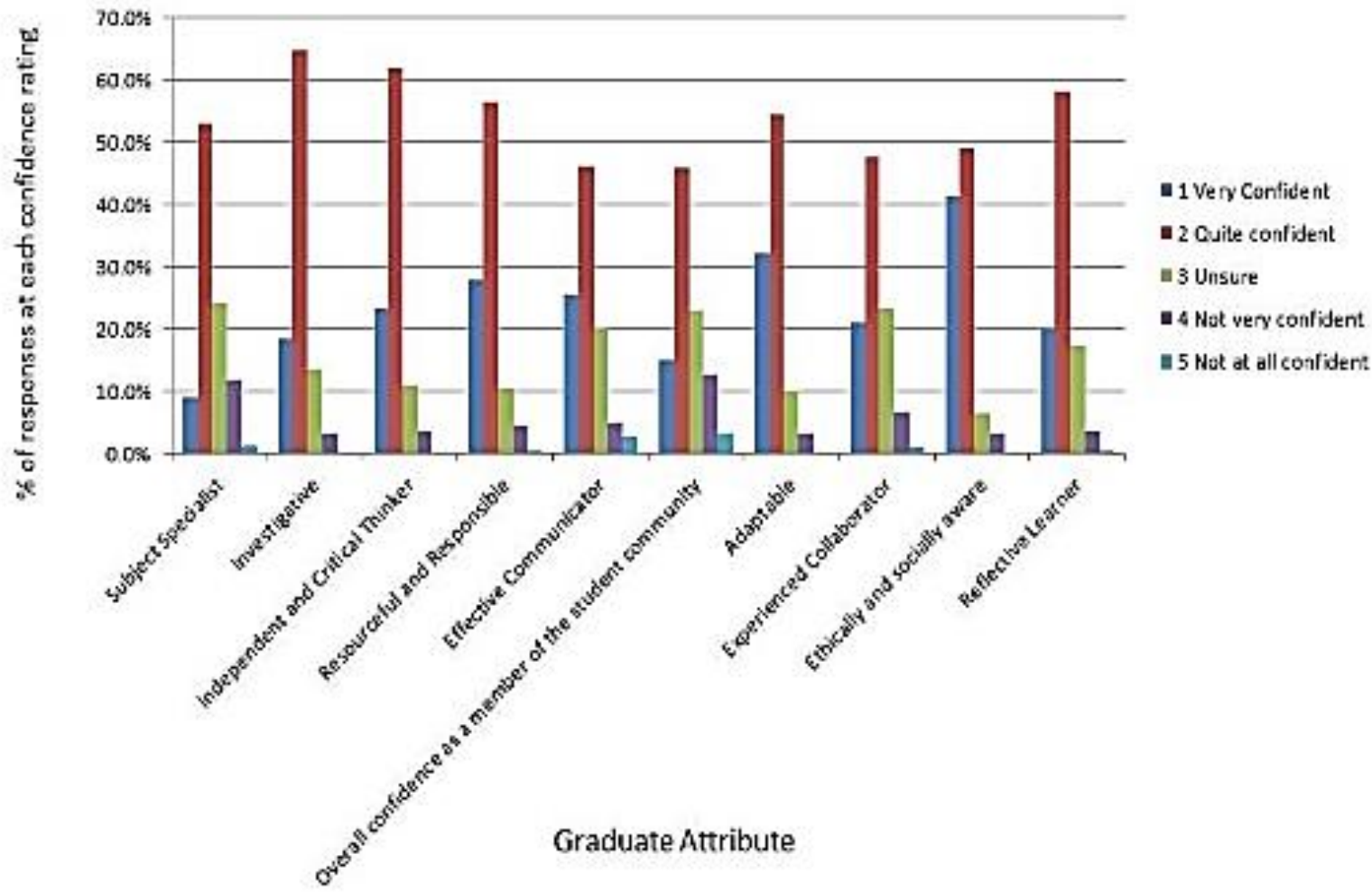

Figure 2 Frequency of rating by GA at Time 2 (post-intervention) 
Where am I now and where do I want to be? Developing awareness of graduate attributes in pre-honours students

\section{Student Engagement}

Consultation with students on the integrated and optional activities elicited positive feedback. However, students felt that class activities and workshops should be aligned more closely with their subject of study, and were eager to find strategies to develop their GAs, e.g. "I feel like we spoke a lot about how we develop GAs, but not how we would then go on to actually use them. So examples of attributes in relation to specific jobs would be helpful". A number of students stated that they found the STAR approach helpful while one stated, "The information about common interview questions and how to prepare for them was very helpful." At the same time, one student felt they had insufficient time to prepare: "warn/give students time to prep for this practical element should they want to practice in the workshop."

\section{Discussion}

The outcomes of the integrated approach in the Level 2 psychology classes suggest that embedding a reflective exercise increased selfefficacy in each of the GAS, with the exception of overall confidence as a member of the student community. This may reflect that students at this level are engaging less in cocurricular activities, and future work could address this by signposting the benefits of such opportunities earlier in the degree programme. In light of Wakeham's (2016) recommendation for courses to more explicitly map links between assessments and GAs, further development could focus on how to assess and provide feedback on the reflective activities. The outcome of the voluntary careers sessions indicated that those that attended felt they increased their knowledge of interview questions, person specifications and felt more confident about going into an interview. As a proportion of the class, attendance at the workshops was low (3\%), and less than the networking event. The involvement of a student intern in the networking event may have contributed to the capacity turnout in that the intern used his own networks to promote the event and to approach companies and contacts. Encouraging active student participation (Bovill, Cook-Sather, Felten, Millard, \& Moore-Cherry, 2016) by working in partnership with students on the co-creation and promotion of events and workshops may widen the reach of optional careers activities, and provide a sense of ownership. Student comments on the integrated and optional activities reflect previous findings that a one size fits all approach to the embedding of GAs in degree programmes may not be suitable (O'Leary, 2016). Instead, development of a template for reflective activities and workshops, which can be tailored to the degree subject and employers may be more suitable. In conclusion, our integrated and optional activities for STEM undergraduates provide a methodological approach for embedding GAs more systematically and robustly in degree curricula (Wakeham, 2016), and our findings outline the benefits and challenges of engaging students in the process.

\section{Acknowledgements}

We would like to thank Ms Louisa Kuehme for her comments on the class activities.

\section{References}

Akhurst, J. (2005). Enhancing the employability of psychology graduates. York: Higher Education Academy Psychology Network.

Bandura, A. (1986). Social foundations of thought and action: A social cognitive theory. Englewood Cliffs, NJ: Prentice-Hall, Inc.

Barrie, S. C. (2004). A research-based approach to generic graduate attributes policy. Higher Education Research \& Development, 23(3), 261-275. doi:10.1080/0729436042000235391

Bovill, C., Cook-Sather, A., Felten, P., Millard, L. \& Moore-Cherry, N. . (2016). Addressing potential challenges in co-creating learning and teaching: overcoming resistance, navigating institutional norms and ensuring inclusivity in student-staff partnerships. Higher Education, 71, 195-208. doi:10.1007/s10734015-9896-4

Cheng, M., Pringle Barnes, G., Edwards, C., \& Manousos, V. (2015). Transition skills and strategies: self-efficacy Retrieved from: www.enhancementthemes.ac.uk 
Where am I now and where do I want to be? Developing awareness of graduate attributes in pre-honours students

Cowan, J. C., D. . (2012). The learner's role in assessing higher level abilities. Practitioner Research in Higher Education, Vol 6, (No 1), $12-22$.

Curry, G. B., Copsey, D., Brown, C., Harrison, J., Wightwick, J., Deeley, S., Coupar, S.A., Voute, L., Croudace,R., Woodruff, S., \& Campbell, L. (2012). Mahara and reflection to illustrate development of graduate attributes. Paper presented at the 5th Annual University of Glasgow Learning and Teaching Conference: Empowering Student Learners in Higher Education., University of Glasgow, Glasgow, Scotland, U.K. http://www.gla.ac.uk/services/learningteaching levents/annuallearningandteachingconference /2012conference/.

Gbadamosi, G., Evans, C., Richardson, M., \& Ridolfo, M. (2015). Employability and students' part-time work in the UK: does self-efficacy and career aspiration matter? British Educational Research Journal, 41(6), 1086-1107. doi:10.1002/berj.3174

Gore, P. A. (2006). Academic self-efficacy as a predictor of college outcomes: Two incremental validity studies. Journal of Career Assessment, $\quad 14, \quad 92-115$. doi:doi:10.1177/1069072705281367

Green, W., Hammer, S., \& Star, C. (2009). Facing up to the challenge: why is it so hard to develop graduate attributes? Higher Education Research \& Development, 28(1), 17-29. doi:10.1080/07294360802444339

Higher Education Academy (2015). Framework for embedding employability-inHigher Education. Retrieved from www.heacademy.ac.uk/frameworkstoolkits/toolkits

Hugh-Jones, S. S., E. . (2007). Employability: How to maximise the employability of Psychology graduates. Retrieved from https://www.heacademy.ac.uk/sites/default/file s/p20070404 employability miniproject final report.pdf
Morris, S., Cranney, J., Jeong, J. M., Mellish, L. (2013). Developing psychological literacy: Student perceptions of graduate attributes. Australian Journal of Psychology, 65(1), 54-62. doi:10.1111/ajpy.12010

Nicol, D. (2010). The foundation for graduate attributes: developing self regulation through self and peer-assessment. Retrieved from: http://www.enhancementthemes.ac.uk/

O'Leary, S. (2016). Graduates' experiences of, and attitudes towards, the inclusion of employability-related support in undergraduate degree programmes; trends and variations by subject discipline and gender. Journal of Education and Work, 1-22. doi:10.1080/13639080.2015.1122181

UCAS (2011). Balancing your work and study. Retrieved from https://www.ucas.com/ucas/conservatoires/fin ance-and-support/managingmoney/balancing-work-and-study

University of Glasgow (2016). What are Graduate Attributes? Retrieved from http://www.gla.ac.uk/students/attributes/

Wadkins, T. A., \& Miller, R. L. (2011). Structuring the capstone experience in psychology. In E. A. R. L. Miller, B. Marsteller Kowalewski, B. C. Beins, K. D. Keith, \& B. F. Peden (Eds.), (Ed.), Promoting student engagement (Vol. Vol. 1: Programs, techniques and opportunities, pp. 95-102). Washington, DC.: Society for the Teaching of Psychology, US.

Wakeham, W. (2016). Wakeham Review of STEM Degree Provision and Graduate Employability. Retrieved from https://www.gov.uk/government/uploads/syste m/uploads/attachment data/file/518582/ind16-6-wakeham-review-stem-graduateemployability.pdf 